has always found the carbon dioxide to have been completely absorbed.

The stopper with the pipette is now partly withdrawn from the flask $B$, the pipette rinsed out several times into the flask and water added to the Ioo cc. mark. After mixing, a $25 \mathrm{cc}$. portion is taken for titration. The advantages of this apparatus are as follows:

I. Ease of construction.

2. Ease of manipulation.

3. It permits of distilling over as much of the liquid as desired, to drive out the residue of carbon dioxide, without experiencing any annoyance due to sucking back of the potassium hydroxide solution into the condenser.

4. It eliminates the necessity of transferring the alkaline solution to another vessel before making it up to a definite volume, thus also keeping it away from contact with the carbon dioxide of the air.

The following table shows some results obtained with the apparatus here described.

SAMPLE.
$\mathrm{Na}_{2} \mathrm{CO}_{3}$
$\mathrm{Na}_{2} \mathrm{CO}_{3}$
$\mathrm{Na}_{2} \mathrm{CO}_{3}$
$\mathrm{Na}_{2} \mathrm{CO}_{3}$
Baking powder No. 1
Baking powder No. 1
Baking powder No. 1
Baking powder No. 1
Baking powder No. 1
Baking powder No. 2
Baking powder No. 2
Baking powder No. 3
Baking powder No. 3
Limestone
Limestone
Limestone

\begin{tabular}{|c|c|}
\hline $\mathrm{CO}_{2}$ FOUND. & PER CEN \\
\hline$\ldots \ldots$ & 39. \\
\hline & \\
\hline 2nd run. & 39.45 \\
\hline $\mathrm{e} \mathrm{CO}_{2}, 1 \mathrm{st}$ & 8.10 \\
\hline$n \ldots \ldots$ & 8.02 \\
\hline lation.......... & 8.10 \\
\hline $\mathrm{O}_{2}$, 1st distillation $\ldots \ldots \ldots \ldots \ldots$ & 11.01 \\
\hline $\mathrm{O}_{2}, 2 \mathrm{nd}$ dist & 10.91 \\
\hline le $\mathrm{CO}_{2}, 1 \mathrm{~s}$ & 8.76 \\
\hline le $\mathrm{CO}_{2}, 2 \mathrm{n}$ & 8.62 \\
\hline ble $\mathrm{CO}_{2}, 1$ st & 10.74 \\
\hline able $\mathrm{CO}_{2}$, 2nd distillation & 10.91 \\
\hline etric method.. & 40.25 \\
\hline etric, & 40.23 \\
\hline rolumetric, 2nd titration... & 40.40 \\
\hline
\end{tabular}

When the method is used for the determination of the available carbon dioxide in baking powders, where it is necessary to decompose the sample with water, frothing occurs during the heating of the solution. This makes it difficult to distil over enough water to drive out the last of the carbon dioxide. In order to overcome this difficulty, when the distillation was carried as far as was practicable, the distilling flask was filled with water through the dropping funnel, thus forcing any carbon dioxide into the $a b-$ sorbing flask.

By using a solution of $25-3 \circ$ per cent. alcohol instead of pure water, for decomposing the baking powder, it was found possible to prevent excessive frothing. ${ }^{x}$ One could then clear the flask of the last portion of carbon dioxide by distilling over a little of the liquid and thus do away with the necessity of filling the flask with water.

It is necessary to determine the carbon dioxide in the potassium hydroxide solution used as the absorbing reagent and to apply the correction in each titration.

In the writer's experience with the volumetric method for carbon dioxide the greatest source of

1 For this improvement of the method, the writer is indebted to Prof. G. W. Cavanaugh of Cornell University. error is in the titration. The end point with phenolphthalein must be approached with care as the disappearance of the red color is rather slow.

ITHACA, NEW YORK.

\section{A MODIFICATION OF THE SWEENEY METHOD FOR CRUDE FIBER.}

By CORNELIA KENNEDY.

Received May 6, 1912.

The method for the determination of crude fiber as recently modified by $M$. O. Sweeney ${ }^{I}$ does not prove entirely satisfactory for all kinds of feed stuffs, especially those which are rich in protein. In his method an ether extracted sample of feed is first boiled for $3 \circ$ minutes with r.25 per cent. sulphuric acid. This acid solution is neutralized with ro per cent. sodium hydroxide and $200 \mathrm{cc}$. of a boiling 2.65 per cent. sodium hydroxide solution added and boiled for 30 minutes. The sample is then filtered, washed, dried, weighed, incinerated and reweighed.

The acid dissolves certain nitrogenous bodies, pentosans, gums, etc., and when the alkali solution is added a heavy precipitation of some of these materials is caused. This precipitate is weighed with the crude fiber and consequently materially increases the percentage amount of fiber.

The following modification of the Sweeney method does away with this difficulty and gives results which check, within the limits of error, with the official method.

As in the above method the prepared sample is first boiled with $200 \mathrm{cc}$. of a 1.25 per cent. sulphuric Official method. Sweeney's method. Sweeney's modified.

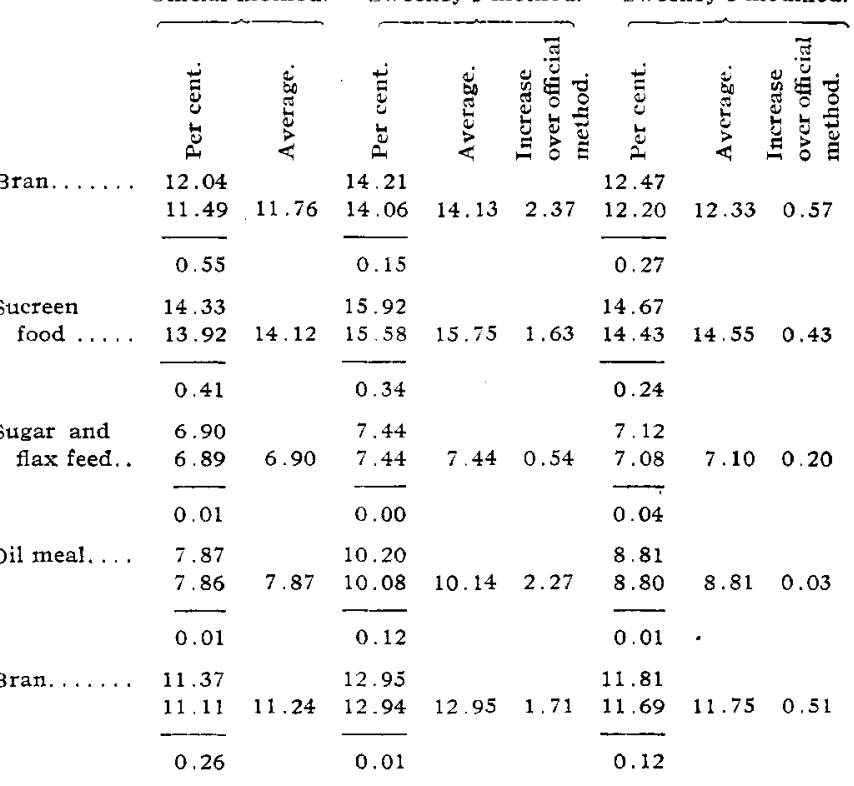

acid. Neutralization is done away with, by making the alkali solution of such strength that it both neutralizes the acid and leaves the $400 \mathrm{cc}$. of 1.25 per cent. sodium hydroxide; $200 \mathrm{cc}$. of a boiling 3.52 per cent. sodium hydroxide are therefore added, and the whole boiled 30 minutes. The solution and fiber are then thrown onto a linen filter (which works more rapidly than a gooch because of the nature of the solution) and washed free of alkali. (Suction may be used to

${ }_{1}$ U. S. Dept. Agr., Bur. of Chem., Bull. 137, 157. 
cause a more rapid filtration.) The fiber is then thoroughly washed with boiling 1.25 per cent. sulphuric acid, which will remove the material precipitated by the addition of the alkali, washed free of acid, removed from the linen filter to a crucible, dried, weighed, incinerated and reweighed.

The Sweeney method has a great advantage over the official method by doing away with a filtration and thus saving time. This advantage is preserved in the modification of the Sweeney method.

The preceding table shows the results of all three methods on 5 different samples of feeds.

DEPARTMENT OF AGRICULTURE,

LNIVERSity OF MinNesota, St. PAUl.

\section{STUDIES ON SOIL HUMUS.}

By SHERMAN LEAVITT.

Received January 30, 1912.

Humus is recognized as one of the most valuable constituents of a soil and yet little is known as to its composition. Fifty or sixty years ago, chemists thought they had shown humus to have a definite chemical composition with percentages of carbon, hydrogen, nitrogen and oxygen constant. According to their theory, humus was a salt of humic acid (also considered a definite chemical compound) which, upon oxidation, yielded simpler hypothetical organic acids called crenic and apocrenic. Although, as far as the writer knows, they had little or no experimental proof, many of these theories have been held to by some until quite recently.

In spite of all the work which has been done during the past fifty years, but little is known about humus. It is the belief of the writer that most chemists who have worked on the subject within the last fifteen years will agree that it is far from being a definite compound, and, in fact, that it is as variable in composition, if indeed not more so, as the different soils of which it is a component part.

Why does soil $A$ accumulate humus matter readily while soil $B$, under similar conditions of treatment, etc., apparently makes no appreciable and permanent improvement?

We are working at this probiem along two general lines: First, under field conditions; second, under laboratory control.

This article will be confined mainly to the second class, as definite results from the field cannot be obtained under many years.

In the laboratory, large samples of soils that are under field experimentation are being used. These were procured from car-load lots, thoroughly mixed, so that the samples are quite representative of the types under investigation. These samples represent four distinct type soils in different sections of Tennessee and were chosen for the reason that each one was the poorest soil of that particular type. It was thought of interest to include a Florida Everglade soil, rich in humus, for comparison in the chemical work.

As most of the humus matter in Tennessee soils is present in the first six inches of soil, the laboratory work on humus has been confined to this layer.

At the beginning of this work it was deemed advisable to remove completely, under the same conditions of extraction, the humus matter from a large quantity of each one of these soils. Under similar conditions of preparation, the humus matter obtained from each one of these soils ought to be at least approximately comparable. Any appreciable difference in the approximate composition of the several samples of humus might have great significance and might point to some quite different behavior of the humification process in the several soils. This may be taken as the key-note of the following investigation:

Anumber of quantitative chemical methods for the determination of percentage of humus in soils were subjected to examination for their respective values. The investigation earlier reported ${ }^{x}$ brought out some valuable points, notably that the humus matter from different soils could be absolutely different both in appearance and in behavior toward reagents. Several of the methods in use for the determination were found unreliable on Tennessee solls for the reason that they failed to show all of the organic matter in the ammonia solutions.

In this later investigation, dealing more specifically with the properties of the several humus samples, a description of the method of procedure in the preparation of the samples of humus will be given. During the work, it was deemed advisable to modify the method of removing clay from the samples, the reasons for which will be given.

Method A.-Five hundred grams of the air-dried soil were extracted with I per cent. hydrochloric acid, according to the Official Method, washed free from acid and then extracted three days with 4 per cent. ammonia, allowed to settle and the supernatant liquid drawn of:. Fresh 4 per cent. ammonia was added and the process repeated. The soil was extracted three times with successive portions of 4 per cent. ammonia, about two liters of solution being used for each extraction. The last extraction contained very little coloring matter. The extractions were all evaporated to dryness in a large porcelain dish on the hot water bath, baked for some hours, and cooled. The residue was then extracted with about two liters of 4 per cent. ammonia, washed by decantation and filtered. A large proportion of the flocculated clay was retained on the filter paper, which was thoroughly washed with 4 per cent. ammonia. The process of evaporation, baking, extraction, washing and filtering, was repeated a number of times until the filtrate appeared absolutely clear. This was then evaporated to dryness in a large beaker to drive off the excess of ammonia; dissolved in hot, distilled water; filtered and washed into a $500 \mathrm{cc}$. graduated flask; cooled and $r$ cc. of strong ammonia added to prevent fermentation; then made up to the mark. The solution was thoroughly mixed and allowed to stand for two months to give finely divided clay, still in suspension, a chance

1 "Soil Humus as Determined by Different Methods," THIS Jourval, 2, 269 